Tropelías. Revista de Teoría de la Literatura y Literatura Comparada, número extraordinario 1 (2017) 3 Publicaciones de José Enrique Martínez Fernández

\title{
PUBLICACIONES DE JOSÉ ENRIQUE MARTÍNEZ FERNÁNDEZ
}

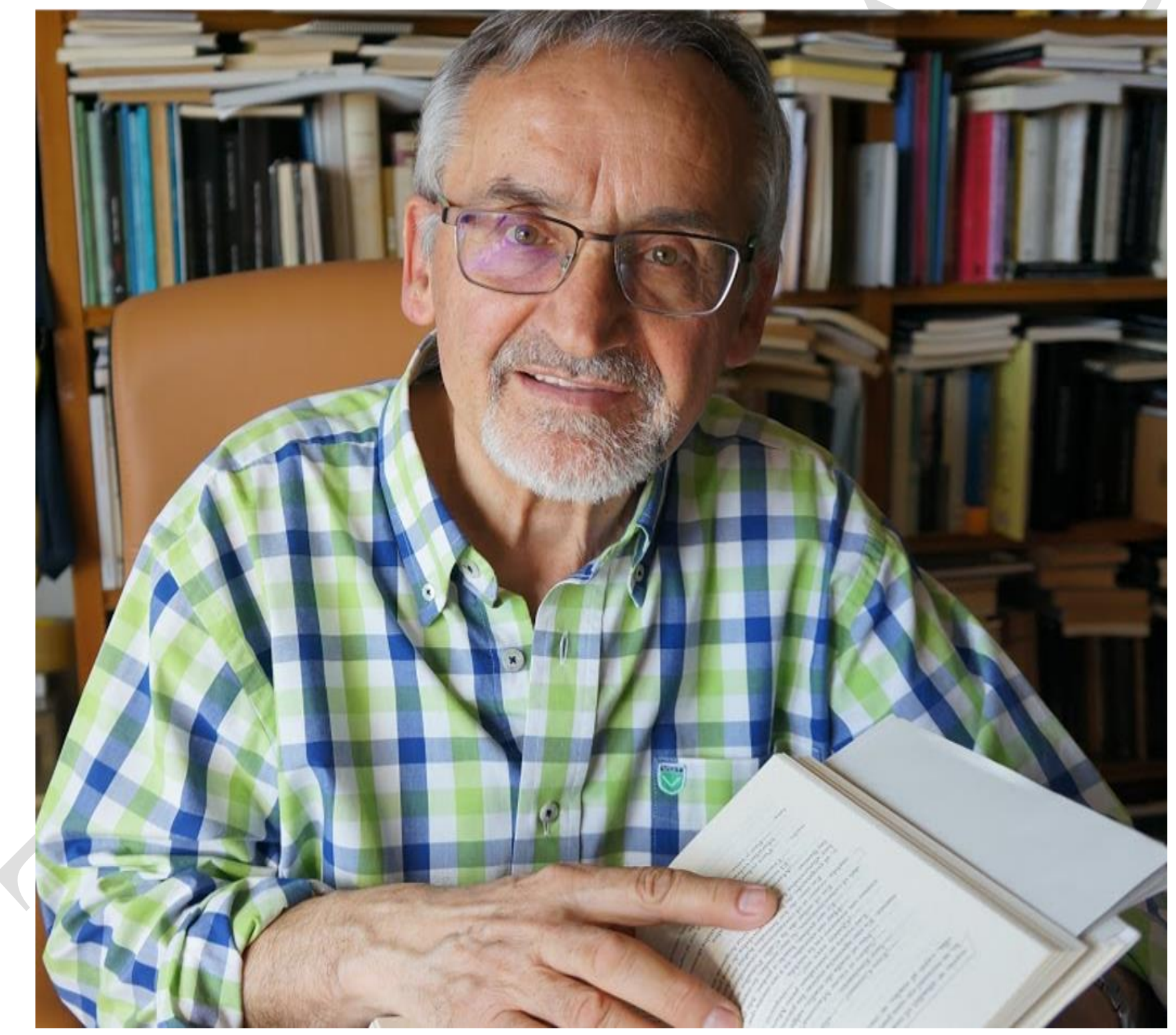

\section{LIBROS}

De creación

(1977): Al aire de tu vuelo. León (en colaboración con Gregorio Montero). 
- (1985): Ciclos de amor y viento. Institución Fray Bernardino de Sahagún, Col. Provincia, León.

- (2009): «Sin benevolencia», en I. CANTÓN MAYO, coord., Narraciones de la escuela. Barcelona, Davinci, pp. 107-110 (Relato).

\section{De investigación}

— (1991): Victoriano Crémer, el hombre y el escritor. León, Ayuntamiento.

_ (1994): La ciudad inventada. Diputación Provincial de León, col. Breviarios de la Calle del Pez, León.

_ (1996): El fragmentarismo poético contemporáneo. Fundamentos teórico-críticos. Universidad de León.

- (1997): Didáctica de la Lengua y Literatura (coord. con Joaquín Serrano). Oikos-Tau, Barcelona.

- (1997): Penumbra vital, literaria y educativa de Manuel Santamaría (con Isabel Cantón Mayo). Universidad de León.

- (1999) (Coord.): Trilcedumbre. Homenaje al profesor Francisco Martínez García. León, Universidad.

— (2001): La intertextualidad literaria (Base teórica y práctica textual). Madrid, Cátedra.

— (2000): Ángel García Aller, poeta. Desde la ausencia (Estudio y antología). León, Universidad.

— (2002): Estudios de Literatura Comparada. Norte y Sur. La sátira. Transferencia y recepción de géneros y formas textuales, Actas del XIII Simposio de la Sociedad Española de Literatura General y Comparada (coord. Martínez Fernández et alii). León, Universidad de León.

- (2005): Nostalgia de una patria imposible. Estudios sobre la obra de Luis Cernuda (eds. J.

Matas, J. E. Martínez, J. M. Trabado). Madrid, Akal.

_ (2005): El mundo del padre Isla (coords. José Enrique Martínez Fernández y Natalia Álvarez Méndez). Universidad de León.

(2005): Grupo «Cántico» de Córdoba. Comentarios de poemas. Madrid, Arco Libros.

(2007): El siglo de oro de las letras leonesas (coord. con Alfonso García Rodríguez y Nicolás Miñambres). León, Edilesa.

- (2009): Victoriano Crémer. Cien años de periodismo y literatura (Ed. José Enrique Martínez). Salamanca, Fundación Instituto Castellano y Leonés de la Lengua.

- (2010): La voz entrecortada de los versos. Nuevos estudios sobre el encabalgamiento. Barcelona, Davinci.

(2010): Voces del Noroeste. Capítulos de Literatura Berciana. León, Eolas. 
Tropelías. Revista de Teoría de la Literatura y Literatura Comparada, número extraordinario 1 (2017) 5

Publicaciones de José Enrique Martínez Fernández

— (2015): El viaje de la palabra. Estudios sobre la obra de Ramón Carnicer (Ed.). León, Eolas.

- (2017): El lienzo de la página (La poesía y las otras artes). Universidad de León, Área de Publicaciones.

\section{Estudios y ediciones críticas}

- (1983): Poesías Completas de Garcilaso de la Vega (ed., pról. y notas). Tárraco, Tarragona.

_ (1987): El alcalde de Zalamea, de Calderón de la Barca (ed., pról. y notas). Anaya, Madrid.

— (1989): Antología de la poesía española (1939-1975) (ed., pról. y notas). Castalia (col. Castalia

Didáctica), Madrid.

_ (1990): Teatro Cómico Breve (ed., pról. y notas). Edelvives, Madrid. (2ª ed., 1993; $3^{\mathrm{a}}$ ed., 1994; $4^{a}$ ed., 1998; $5^{a}$ ed., 1999; $6^{a}$ ed. Revisada, 2014).

_ (1991): Generación del 98 (ed., pról. y notas). Edelvives, Madrid, 1991 (2 ed., 1999).

— (1997): Antología de poesía española (1975-1995) (ed., pról. y notas). Castalia (col. Castalia Didáctica), Madrid.

- (2004): En la luz respirada (Sepulcro en Tarquinia, Noche más allá de la noche, Libro de la mansedumbre), de Antonio Colinas (ed., intr. y notas). Cátedra (Letras Hispánicas), Madrid.

- (2007): Diez nuevas voces de la poesía leonesa, VV. AA., (Coord. Con A. García y N. Miñambres), con prólogo de J. E. Martínez. León, Edilesa.

— (2009): Los signos de la sangre (Poesía 1944-2004), Victoriano Crémer (Ed. y prólogo de José Enrique Martínez). Madrid, Calambur (2 tomos).

- (2013): Los mundos interiores de Antonio Pereira (Ed. y presentación de José Enrique Martínez), León, Universidad de León / Fundación Antonio Pereira.

— (2014): Los médicos leen a Antonio Pereira (Ed. y presentación de José Enrique Martínez). León, Universidad de León / Fundación Antonio Pereira.

(2015): Antonio Pereira y los lectores de Poniente (coord. y presentación de José Enrique Martínez). León, Universidad de León / Fundación Antonio Pereira, Presentación, pp. 9-28.

\section{ARTÍCULOS Y CAPÍTULOS DE LIBRO}

_ (1982): «Itinerario de La Pícara Justina», Tierras de León, núm. 47, pp. 113-135.

- (1983): «León como escenario literario en la novelística española actual», Tierras de León, núm. 53, pp. 107-120.

_ (1984): «Espadaña y el 27 del Interior», Tierras de León, núm. 56, pp. 89-104.

— (1987): «Presencias de Federico García Lorca en León», Tierras de León, núm. 68, pp. 67-78. 
— (1988): «Un cruce de cartas entre Félix Gordón Ordás y Victoriano Crémer», Tierras de León núm. 72, pp. 57-64.

_ (1989): «Nuevos cantos de vida y esperanza para un tiempo de soledad», Tierras de León núm. 75, pp. 89-104.

- (1988): «La belleza conseguida en los dos nuevos libros de Antonio Colinas», Lirba núms. 13 y 14, Abril-Agosto, pp. 33-36.

- (1990): «En torno a la poética de Antonio Colinas», Lirba, núm. 17, Septiembre, pp. 38-41.

- (1991): «Ramón Carnicer en Laye: búsqueda y defensa de la autenticidad», en Vida y obra de Ramón Carnicer, Universidad de Oviedo, pp. 53-80.

_ (1991): «A manera de prólogo (palabras para Jesús Díez Fernández)», prólogo al libro de poemas de Jesús Díez Fernández titulado Nogal de Pergamino. Ed. Andrómeda, col. de poesía Tagore, Madrid, pp. 9-13.

— (1991): «Biografía (de Ricardo Gullón)», en León (Revista de la Casa de León en Madrid), núms. 349-350, pp. 25-28.

— (1991): «Bibliografía» (de Ricardo Gullón), en León (Revista de la Casa de León en Madrid), núms. 349-350, pp. 33-34.

_ (1992): «Victoriano Crémer: el poeta en su rincón», en 1992 Anuario de Castilla y León, Ámbito Ediciones, pp. 381-387.

(1993): «La obra literaria de Ramón Carnicer», 1993 Anuario de Castilla y León, pp. 461-469.

(Reeditado, con actualizaciones, con el título «La obra literaria e investigadora de Ramón Carnicer», en El viaje de la palabra. Estudios sobre la obra de Ramón Carnicer (Ed.). León Eolas, 2015, pp. 17-40).

(1993): «Poesía leonesa actual» (presentación y selección), El Ciervo, número 510-511, Septiembre-Octubre, pp. 21-24.

(1993): «Victoriano Crémer, al día», prólogo al libro La escondida senda, de Victoriano Crémer. Junta de Castilla y León, pp. 9-12.

(1994): «Claudio Rodríguez. La poesía como un don», 1994 Anuario de Castilla y León, pp. 477-484.

(1994): «Noticia de un escritor leonés: Nemesio Fernández», en Estudios Humanísticos (Filología), número 16, Universidad de León, pp. 207-222.

- (1994): «Dos polos en la poesía española de los años cuarenta (Homenaje a Espadaña cincuenta años después de su primera salida)», Tierras de León núms. 93-94, pp. 147-160. 


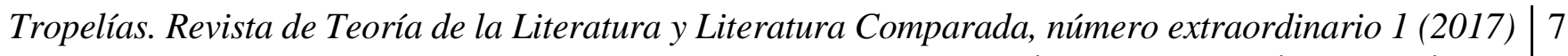
Publicaciones de José Enrique Martínez Fernández 7

(1995): «Oralidad y escritura. Poesía oral y poesía escrita», En Estudios Humanísticos (Filología), núm. 17, Universidad de León, pp. 229-243.

(1995): «La "Escuela de Astorga”, Espadaña y los espadañistas (con una carta inédita de Leopoldo Panero)», en La escuela de Astorga. Ayuntamiento de Astorga / Diputación de León, pp. 163-169.

(1995): «Últimas y penúltimas promociones poéticas leonesas», en Tierras de León, núms. 9798, pp. 137-150.

_ (1996): «El medio ambiente en la prensa leonesa», en Prensa en las aulas II (Actas del II Congreso Internacional "Prensa en las aulas", Zamora, 12-14 de octubre de 1995, coord. Bartolomé Crespo). Editorial CCS, Madrid, pp. 237-241 (en col. con I. Cantón Mayo).

_ (1996): «Antonio Gamoneda: la voz del corazón cansado», en 1996 Anuario de Castilla y León. Ámbito Ediciones, Valladolid, pp. 327-334.

- (1996): «Dimensiones de la ficción. A propósito de La orilla oscura», en Mundos de ficción, II (Actas del VI Congreso Internacional de la AES, Investigaciones Semióticas VI), eds. Pozuelo Yvancos, J. M. y Vicente Gómez, F.. Universidad de Murcia, Murcia, pp. 1007-1112.

(1996): «En torno a la comunicación poética: Lectura /lecturas del discurso poético actual», en Estudios Humanísticos (Filología), núm. 18. Universidad de León, pp. 245-2.

(1997): «Los actuales enfoques teórico-críticos de la literatura«», en Serrano, J. y Martínez, J.

E. (Coords.), Didáctica de la Lengua y Literatura. Oikos-Tau, Barcelona, pp. 61-84.

(1997): «El mundo literario de Antonio Pereira», en 1997 Anuario de Castilla y León. Ámbito Ediciones, Valladolid, pp. 313-320.

_ (1997): «Desarticulación de metros clásicos por medio del encabalgamiento continuado», en En la esfera semiótica lotmaniana. Estudios en honor de Iuri Mijáilovich Lotman (Manuel Cáceres, ed.). Episteme (col. Eutopías / Maior), Valencia, pp. 295-304.

(1997): «De la influencia literaria a la huella textual», en Exemplaria, Revista Internacional de Literatura Comparada, vol. 1, 1997 (Universidad de Huelva), pp. 179-200.

(1997): «La voz del Renacimiento en la obra de Antonio Colinas: Tradición y actualidad», en El viaje hacia el centro [La poesía de Antonio Colinas] (Antonio Colinas et alii). Calambur, Madrid, pp. 91-102.

(1997): «Problemática del autobiografismo: las memorias de Ramón Carnicer», en Tierras de León, núm. 102, agosto, 1997, pp. 103-114. (Reeditado en El viaje de la palabra. Estudios sobre la obra de Ramón Carnicer, León Eolas, 2015, pp. 169-187). 
- (1998): «Experiencia y experimentación (res /verba) en la poesía española última», en Estudios Humanísticos (Filología), núm. 20, Universidad de León, pp. 211-224.

(1998): «Una experiencia de trabajo en grupo para la elaboración de materiales curriculares para la didáctica de la lengua y literatura españolas», en Enseñanza de las lenguas: comunicación y tecnología (Actas del I Congreso Nacional de Didáctica de las Lenguas en el Sistema Educativo Español, León, 24-26 de abril de 1997, coords. Miguel Fuertes González y Trinidad-Aránzazu Fernández Martínez). Grupo Editorial Universitario, Granada, pp. 271-278. (En colaboración con Joaquín Serrano Serrano).

(1998): «La recepción del Renacimiento en la obra de Antonio Colinas», en Actas Congreso Internacional sobre Humanismo y Renacimiento, vol. II (coords. J. Matas, J. M. Trabado, M. L. González y M. Paramio). Universidad de León, León, pp. 487-494.

(1998): «Prometeo frente a Orfeo: poética de la renuncia frente a poética de la plenitud», en Mitos. Actas del VII Congreso de la Asociación Española de Semiótica (ed. T. Blesa). Zaragoza, Anexos de Tropelías, col. Trópica, 4, pp. 60-66.

- (1999): «Eugenio de Nora y Espadaña», en VV. AA. Homenaje de la Cepeda a Eugenio de Nora. Diputación de León / Junta de Castilla y León..., Zamora, pp. 33-52.

_ (1999): «Sobre el encabalgamiento», en Tropelías, núms. 7 y 8, 1996- 1997, pp. 193-215.

— (1999): «El pensamiento teórico-crítico de Francisco Martínez García», en Martínez Fernández,

J. E. (coord.), Trilcedumbre. Homenaje al profesor Francisco Martínez García. León, Universidad, pp. 295-304.

- (1999): «Caballos de luz en la poesía de Ángel Crespo», en Ángel Crespo: una poética iluminante (ed. e intr. de J. M $\mathbf{M}^{\mathrm{a}}$ Balcells). Ciudad Real, Diputación (Biblioteca de Autores Manchegos), pp. 223-236.

(1999): «Burla, sátira y humor en Fray Gerundio de Campazas (Huellas de la comicidad carnavalesca)», en EPOS, XV, pp. 175-197.

(1999): «Territorios de la memoria en la narrativa de Luis Mateo Díez», en Luis Mateo Díez, núm. 4 de Cuadernos de Narrativa. Neuchâtel, Universidad de Neuchâtel, pp. 135-145.

(2000): «Un profesor de Sierra Pambley en Cuba: el Martí de Herminio Almendros» (en colaboración con I. Cantón Mayo), en Literatura de las Américas 1898-1998, vol. II (coords. J. C. González Boixo, J. Ordiz Vázquez y Mª J. Álvarez Maurín). Universidad de León, pp. 753 764.

(2000): «Retrato y nombre propio (huellas literarias y carnavalescas en los retratos de Fray Gerundio de Campazas)», en El retrato literario. Tempestades y naufragios. Escritura y 


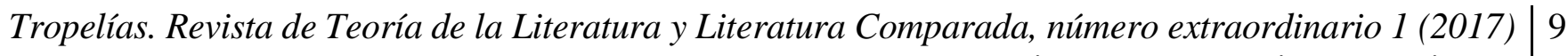
Publicaciones de José Enrique Martínez Fernández

reelaboración. Actas del XII Simposio de la Sociedad Española de Literatura General y Comparada (SELGyC) (Eds. M. A. Márquez, A. Ramírez de Verger, P. Zambrano). Huelva, Universidad, pp. 285-291.

(2000): «Poesía y metapoesía en Eugenio de Nora», en VV. AA., Homenaje a José María Martínez Cachero, vol. III. Oviedo, Universidad, pp. 127-144.

(2000): «Memoria y creación: Tiempo de guerras perdidas, de Caballero Bonald», en J. Romera Castillo y F. Gutiérrez Carbajo (eds.), Poesía histórica y (auto)biográfica (1975-1999). Madrid, Visor, pp. 409-420.

(2000): «Voces sin rostro en la poesía española de fin de siglo», en Miradas y voces de fin de siglo. Actas del VIII Congreso Internacional de la Asociación Española de Semiótica, 2 vols. (Eds. A. Sánchez Trigueros, $M^{a}$ A. Grande Rosales y $M^{a}$ J. Sánchez Montes). Granada, Asociación Española de Semiótica, II, pp. 639-647.

— (2000): «Poesía leonesa última (1975-2000)», en Zurgai, diciembre, pp. 24-30.

_ (2001): «El realismo humanista de Victoriano Crémer» (Presentación y estudio de La casona y biografía). León, Edilesa.

(2001): «Final de verso en partícula átona (Tradición e innovación métrica en la poesía de Antonio Carvajal)», en Signa, 10, pp. 295-311.

(2001): «Experiencia, emoción y reflexión en La plata de los días, de Vicente Gallego», en S. Montesa (ed.), Poetas en el 2000. Modernidad y transvanguardia. Málaga, Publicaciones del Congreso de Literatura Española Contemporánea, pp. 337-347.

- (2001): «La práctica intertextual de Veinte años de poesía española a Nueve novísimos», en De sombras y de sueños. Homenaje a J. M. Castellet (ed. de E. A. Salas Romo). Barcelona, Península.

(2002): «La obra literaria de José Antonio Llamas», en Del rascacielos a la Catedral: un regreso a las raíces. León, Universidad, pp. 361-369.

(2002): «El lirismo acendrado de Gaspar Moisés Gómez (claves de lectura)», en Estudios Humanísticos (Filología), nº 24, Universidad de León, pp. 121-142.

(2002): «El haiku: nuevas propuestas teóricas y creativas», en Estudios de Literatura Comparada. Norte y Sur. La sátira. Transferencia y recepción de géneros y formas textuales, Actas del XIII Simposio de la Sociedad Española de Literatura General y Comparada (coord. Martínez Fernández et alii). León, Universidad de León, pp. 621-632.

(2002): «Elogio de la poesía», en Martínez Fernández, J. E. y otros: Elogio de la poesía. León, Instituto Leonés de Cultura (col. Breves de Tierras de León), pp. 9-21. 
- (2002): «La novela del Patio. Acerca de El centro del aire, de José María Merino», en José María Merino, núm. 6 de Cuadernos de Neuchâtel. Universidad de Neuchâtel, pp. 227-237.

_ (2003): «Serenata y navaja», de Antonio Carvajal: «Selección y estudio», en El corazón y el lúgano (Antología plural) (ed. y coord. Antonio Chicharro). Granada, Universidad, pp. 45-70.

- (2003): «Burla, esplendor y labia en La fuente de la edad», en Estudios Humanísticos, $\mathrm{n}^{\circ}$ 25, pp. 115-126.

(2003): «Retórica de la predicación en Fray Gerundio (Burla, sátira y humor)», en Pulido

Tirado, Genara (ed.), La Retórica en el ámbito de las Humanidades. Jaén, Universidad de Jaén, pp. 75-105.

- (2003): «Modulaciones de la lira en la obra de Antonio Carvajal», en Rhythmica. Revista Española de Métrica Comparada, nº 1, Sevilla, pp. 183-205.

_ (2003): «El padre Isla: la educación y el humor en Fray Gerundio de Campazas» (con Isabel Cantón Mayo), en Revista de Educación, n 332, septiembre-diciembre, pp. 265-274.

- (2003): «Los mundos figurados de Las estaciones provinciales», en Castro Díez, Asunción y Hernández Domingo-Luis (eds.), Luis Mateo Díez: los laberintos de la memoria. Santa Cruz de Tenerife, La Página Ediciones, pp. 139-162.

- (2003-2004): «Emoción y reflexión en Santa deriva, de Vicente Gallego», en Revista Jizo de Humanidades, otoño-invierno, 2003-2004, Año I, núms. 2-3, pp. 52-56.

(2004): «La escritura autobiográfica y palimpséstica de Cuaderno secreto, de Raúl Guerra Garrido», en Estudios Humanísticos (Filología), núm. 26, Universidad de León, pp. 187-201.

- (2004): «Memorias de nuestro tiempo: teóricos y creadores», en Signa, núm. 13, pp. 521-543.

_ (2005): «Lectura de “Ninfa y pastor por Ticiano", de Luis Cernuda», en Nostalgia de una patria imposible. Estudios sobre la obra de Luis Cernuda (eds. J. Matas, J. E. Martínez, J. M. Trabado). Madrid, Akal, pp. 447-466.

(2005): «Primera salida», en IV Centenario. La razón de la sinrazón que a la razón se hace.

Lecturas actuales del Quijote. Instituto Castellano y Leonés de la Lengua, pp. 51-56.

- (2005): «Entre la ebriedad y las pérdidas: vías para la poesía castellana y leonesa contemporánea», en Balcells, José María (coord.), Literatura actual en Castilla y León. Actas del II Congreso de Literatura Contemporánea. Valladolid, Fundación Instituto Castellano y Leonés de la Lengua / Ámbito Ediciones, pp. 279-293.

- (2005): «El mar no es un paisaje. Introducción a la poesía de Amparo Carballo Blanco», en Estudios Humanísticos, núm. 27, pp. 171-192. 
- (2005): «Armonía y ritmo en Antonio Colinas: ajustes métricos en Noche más allá de la noche», en Rhythmica. Revista Española de Métrica Comparada, n² 2, Sevilla, pp. 137-158.

- (2005): «Efectos perlocutivos de la predicación en Fray Gerundio (Variantes léxico-semánticas de la admiratio)», en El mundo del padre Isla (coords. José Enrique Martínez Fernández y Natalia Álvarez Méndez). Universidad de León, pp. 469-482.

- (2005): «Visión espadañista de la realidad poética del momento», en Espadaña: 50 años (coord. Natalia Álvarez Méndez). Universidad de León, pp. 137-152.

- (2006): «Gabriel Celaya abundante y diverso (apunte métrico)», en Extramuros, núms. 38-39 (año X, 2005/2a época), julio, pp. 63-66.

_ (2006): «Víctor Botas: arte, poesía y conciencia temporal», en Víctor Botas y la poesía de su generación. Nuevas miradas críticas (Sánchez Torre, Leopoldo, ed.). Libros del Pexe, Gijón, pp. 281-295.

— (2006-2007): «Precariedad del sujeto poético postmoderno (siluetas, voces, fragmentos: Ildefonso Rodríguez y Olvido García Valdés)», en Prosopopeya, n 5, pp. 187-207.

- (2007): «Oscuro oboe de bruma... Métrica, ritmo e interpretación», en Rhythmica. Revista Española de Métrica Comparada, núms. 3-4, Sevilla, pp. 181-194. (Con Clara Isabel Martínez Cantón).

- (2007): «El título intertextual», en Utrera Torremocha, María Victoria y Romero Luque, Manuel (eds.), Estudios literarios in honores Esteban Torre, Sevilla, Universidad, pp. 273-382. (2007): «Un siglo de poesía», en El siglo de oro de las letras leonesas (coord. José Enrique Martínez, Nicolás Miñambres y Alfonso García). León, Edilesa, pp. 13-131.1

_ (2007): «La poesía de José María Merino. Historia personal y biografía generacional», en Estudios Humanísticos, $\mathrm{n}^{\circ}$ 29, pp. 45-464.

(2007): «Reescrituras: 'El caballero, la muerte y el diablo' de Luis Alberto de Cuenca», en Itinerarios. Revista de Estudios lingüísticos, literarios, históricos y antropológicos. Universidad de Varsovia, vol 6, pp. 263-281. (2008): «Poética del cuadro ausente. Poesía y pintura en Antonio Colinas», en Signa, no 17, pp. 225-248.

(2008): «Las novelas del Bierzo de Raúl Guerra Garrido», en Martínez Fernández, J. E. y Miñambres, N., El Bierzo de Raúl. León, Instituto de Estudios Bercianos, pp. 13-73.

- (2008): «Lecturas interesadas del Quijote (los casos de José María Merino y Antonio Colinas)”, en M. A. Garrido Gallardo y L. Alburquerque (coords.), El Quijote y el pensamiento teóricoliterario. Madrid, CSIC, 2008, pp. 331-340. 
12 Tropelías. Revista de Teoría de la Literatura y Literatura Comparada, número extraordinario 1 (2017) Publicaciones de José Enrique Martínez Fernández

_ (2008): «La estrofa sáfica en dos poetas cordobeses: Ricardo Molina y Pablo García Baena», en Rhythmica. Revista Española de Métrica Comparada, núms. 5-6, Sevilla, pp. 141-155.

_ (2009): “"Pasó a paso”, un poema de Blas de Otero», en Crespo S. Y otros, Teoría y análisis de los discursos literarios. Estudios en homenaje al profesor Ricardo Senabre Sempere. Salamanca, Universidad de Extremadura / Universidad de Salamanca, pp. 235-242.

- (2009): «La poesía última de Victoriano Crémer: decantación de una vida», en Martínez, J. E. (Ed.) Victoriano Crémer. Cien años de periodismo y literatura (Ed. José Enrique Martínez). Salamanca, Fundación Instituto Castellano y Leonés de la Lengua, pp. 117-138.

(2009): «Alguien que trabaja con las manos y se las mancha. Las manos de Velázquez, de Lourdes Ortiz», en Gil Albarelos, Susana y Rodríguez Pequeño, Mercedes (eds.), Musas hermanas. Arte y literatura en el espejo del relato. Cátedra Miguel Delibes, Valladolid, pp. 4970.

(2009): «Efectos expresivos del encabalgamiento en Sonetos espirituales y Estío, de Juan Ramón Jiménez», en Rhythmica. Revista Española de Métrica Comparada, núm. 7, Sevilla, pp. 177-199.

(2009): «Donde Orfeo nos espera con sus acordes. El pensamiento poético de Antonio Colinas», en Pensamiento literario español del siglo XX, 3, (Túa Belsa, Juna Carlos Pueo, Alfredo Saldaña y Enric Sullá (eds.), Anexos de Tropelías, Universidad de Zaragoza, pp. 89-112.

(2009): «Las Médulas, un paisaje cultural y literario», en Las Médulas (VV. AA.). Madrid, Real Academia de Ingeniería, pp. 143-175.

- (2010): «El espacio de los sueños», en Otro Lunes, núm. 116, en http://WWW.otrolunes.com/ html/unos-escriben/unos-escriben-411-a24-p01-2010.html.

- (2010): "Victoriano Crémer, una conciencia crítica ante el mundo", en Turia, núms. 93-94, marzo-mayo, pp. 9-21.

(2010): «Intertextualidad», en Gran Enciclopedia Cervantina, vol. VII. Castalia, pp. 62726280.

(2011): «Los juegos de la rima en un poema de Jaime Siles», en Rhythmica. Revista Española de Métrica Comparada, núm. 8, Sevilla, pp. 95-110.

(2011): «Caballero ya más allá del tiempo (Confluencias y divergencias sobre un mismo asunto)», en Pujante, David (Ed.), Encuentro de generaciones. Mirando hacia el 50. Cátedra Miguel Delibes, Valladolid - Nueva York, pp. 103-1. 
_ (2011): «Literatura y cine», en Martínez Cantón, Clara Isabel y Alonso Guadalupe, Pablo (Coords.), Del papel a la imagen. Universidad de León / Fundación Ciudad de Astorga, León, pp. 37-53.

(2011): «Una lectura de "No túmulo de Martín Vázquez de Arce”, de José Bento», en Santamarta Luengos, José María (Coord.), Homenaje al profesor Justo Fernández Oblanca. León, Universidad de León, pp. 449-456.

(2012): «Acercamientos personales a Leopoldo Panero», en Sandín Pérez, Juan Manuel (ed.), El peso de lo alegre. Recordando a Leopoldo Panero. Madrid, Biblioteca Nueva, pp. 33-39.

_ (2012): «La obra de Antonio González-Guerrero y la poetización del tiempo y de la muerte», en Tierras de León, 128-129, enero-diciembre 2009, pp. 17-45.

_ (2012): «Antonio Colinas: La isla y su simbología», en Lanero, Juan José y Chamosa, José Luis (eds.), Lengua, traducción, recepción. En honor de Julio César Santoyo, vol. II. León, Universidad de León, 2010, pp. 283-314.

(2012): «Poesía, independencia y constitución», en Pablo Alonso González y Clara Isabel Martínez (Coords.), Cine, educación y constitucionalismos. León, pp. 45-66.

(2012): «El juego de los cuánticos. Los microrrelatos de Juan Pedro Aparicio», en Otro Lunes, 24 de septiembre, año 6, Revista Hispanoamericana de cultura (digital).

- (2012): «Obra poética completa, de Antonio Colinas», Ínsula, 792, diciembre, pp. 24-27.

(2012): «Las ideas poéticas de Leopoldo Panero», Astórica. Revista de Estudios Astorganos, 31, pp. 165-181.

- (2012): «Poesía y pintura en la obra de Leopoldo Panero», Revista de Literatura, Vol LXXIV, $\mathrm{n}^{\circ}$ 148, Julio-Diciembre, pp. 541-554.

- (2013): «La estrofa sáfica y sus variantes en la poesía de Antonio Carvajal», en Antonio Chicharro y Antonio Sánchez Trigueros (eds.), Júbilo en el corazón. Homenaje al poeta y profesor Antonio Carvajal. Granada, Universidad de Granada, pp. 108-125.

(2013): «Los fusilamientos de la Moncloa», Debate, $n^{\circ}$ 118, Enero, pp. 80-84.

(2013): «Las relaciones interartísticas. Poesía y pintura en la obra de José Luis Puerto», en Felipe Gómez Alcaraz, F. A. Moreno Serrano y J. F. Villar Dégano (eds.), Literatura y pasión sagrada. Homenaje al profesor Antonio García Berrio. Madrid, Universidad Complutense, pp. 535-544.

- (2013): «Endecasílabos y decasílabos con acento regular en quinta sílaba y otros experimentos rítmicos del poeta mexicano Rubén Bonifaz Nuño», en Rhythmica. Revista Española de Métrica Comparada, Año XII, número 11, Sevilla, pp. 89-113. 
- (2013): «Una mirada sobre la fábula española del XIX. Las fábulas de Pascual Fernández Baeza», en Estudios Humanísticos. Filología, núm. 35, 2013, pp. 35-49.

_ (2014): «Aspectos de lo insólito en la cuentística de José María Merino. Teoría y práctica narrativas», en Pasavento. Revista de Estudios Hispánicos, Vo. II, nº 1, Invierno, pp. 187-205.

- (2014): «Claraboya y el legado de Luis Cernuda», en VV. AA., Claraboya y sus amigos. Eolas, León, pp. 161-164.

_ (2014): «Los médicos de Antonio Pereira», Introducción a Los médicos leen a Antonio Pereira (Ed. y presentación de José Enrique Martínez). León, Universidad de León / Fundación Antonio Pereira, pp. 9-45.

(2014): «La dialéctica dentro-fuera en la poesía de Antonio Colinas», en Francisco Aroca Iniesta (Coord.), Leer la obra de Antonio Colinas, París, Indigo / Centre d’Études Hispaniques d'Amiens, pp. 253-267.

- (2014): «Exentos II. Examen de dos pasiones: la mirada y la reescritura», en Tropelías. Revista de Teoría de la Literatura y Literatura Comparada, núm. 21, pp. 106-112.

_ (2014): «Imágenes de España en la poesía de Andrés Trapìello», en Ínsula, núms. 811-812, julio.

- (2015): «Música y pintura en la poesía de Ángel González», en Prosemas, 1, pp. 127-151.

- (2015): «Ramón Carnicer, viajero por Castilla la Vieja», en Tierras de León, n 132, 2012, pp. 157-186.

- (2015): «Novelización del ocaso colonial español: Las jaulas», en José Enrique Martínez (Coord.), El viaje de la palabra. Estudios sobre la obra de Ramón Carnicer. León Eolas, pp. 121-132.

- (2015): «Ficción y metaficción en la cuentística de José María Merino», en Antonio Chicharro (ed.), Porque eres, a la par, uno y diverso. Estudios literarios y teatrales en homenaje al profesor Antonio Sánchez Trigueros. Granada, Universidad de Granada, pp. 531-545.

(2015): «El adiós a un maestro. Ricardo Senabre, in memoriam», en Anuario de Estudios Filológicos, vol. XXXVIII, pp. 303-320.

\section{Artículos y reseñas en la prensa diaria (suplementos culturales)}

Artículos y reseñas en el suplemento cultural «Filandón» del Diario de León a partir de 1988, como colaborador habitual. 